Glioblastoma (GB) is highly vascularised tumour, known to exhibit enhanced infiltrative potential. One of the characteristics of glioblastoma is microvascular proliferation surrounding necrotic areas, as a response to a hypoxic environment, which in turn increases the expression of angiogenic factors and their signalling pathways (RAS/RAF/ERK/MAPK pathway, PI3K/Akt signalling pathway and WTN signalling cascade). Currently, a small number of anti-angiogenic drugs, extending glioblastoma patients survival, are available for clinical use. Most medications are ineffective in clinical therapy of glioblastoma due to acquired malignant cells or intrinsic resistance, angiogenic receptors cross-activation and redundant intracellular signalling, or the inability of the drug to cross the blood-brain barrier and to reach its target in vivo. Researchers have also observed that GB tumours are different in many aspects, even when they derive from the same tissue, which is the reason for personalised therapy.

An understanding of the molecular mechanisms regulating glioblastoma angiogenesis and invasion may be important in the future development of curative therapeutic approaches for the treatment of this devastating disease.

Key words: glioblastoma, signalling pathways, angiogenesis.

Contemp Oncol (Pozn) 2016; 20 (2): 109-118 DOI: $10.5114 /$ wo.2015.56122

\section{New perspectives in glioblastoma antiangiogenic therapy}

\author{
Alisa Madalina Popescu ${ }^{1^{*}}$, Stefana Oana Purcaru ${ }^{1^{*}}$, Oana Alexandru ${ }^{2}$, \\ Anica Dricu ${ }^{1}$
}

${ }^{1}$ Unit of Biochemistry, University of Medicine and Pharmacy of Craiova, Craiova, Romania

${ }^{2}$ Department of Neurology, University of Medicine and Pharmacy of Craiova and Clinical Hospital of Neuropsychiatry Craiova, Craiova, Romania

*Authors contributed equally to this work.

\section{Introduction}

Glioblastoma (GB), first described in 1926 in the classification of brain tumours by Cushing, is the most common primary brain cancer among adults and the most aggressive malignant brain tumour. GB has an incidence of 1.26 : 1 (men vs. women) and a median survival rate of 13-16 months after standard therapy consisting of maximal resection, radiotherapy, and chemotherapy with temozolomide. Unfortunately, the prognosis is poor with a survival rate of $5 \%$ at five years; there is a small increase in the survival rate for patients diagnosed under the age of 20 . Only $10 \%$ of these types of malignant tumours are secondary neoplasm, evolved from low-grade brain tumours (e.g. anaplastic astrocytoma). The remaining $90 \%$ of GB are de novo glioblastoma multiforme and have a rapid progression of only three months, compared with the secondary glioblastoma that has a progression time of 4-5 years [1-3]. Glioblastomas are highly vascularised tumours, known to exhibit enhanced infiltrative potential.

Angiogenesis is a central process in cancer progress by forming new capillaries from pre-existing vessels using endothelial cell proliferation, migration, and new lumen organisation, succeeding the signalling of growth factors, proteins, and proteolytic enzymes. A number of studies investigated the different types of angiogenesis implicated in tumour development: sprouting angiogenesis (the first studied form of vasculogenesis), intussusceptive angiogenesis, vasculogenic mimicry, and vessel co-option [4-6].

In recent years, new approaches in chemotherapy have targeted specific receptors such as vascular endothelial growth factor receptor (VEGFR), platelet-derived growth factor receptor (PDGFR), fibroblast growth factor receptor (FGFR), and epidermal growth factor receptor (EGFR), which are implicated in angiogenesis, tumour cell proliferation, and adhesion. Angiogenic receptors well studied in brain tumour include: EGFR, VEGFR, and PDGFR. VEGFR is involved in glioblastoma progression through several mutations, such as tumour protein p53 (TP53) and protein kinase B/phosphatidylinositol 3-kinase (PIK3R1/PIK3CA). p53 (TP53) and PIK3R1/PIK3CA fail to inhibit VEGF, which in turn stimulate abnormal secretion of VEGF and VEGFR. EGFR overexpression, mainly by EGFRvIII mutation, occurring in $30-70 \%$ of primary GB is the most frequent mutation; its overexpression activates EGFR - phosphatidylinositol 3-kinase (PI3K) pathway. Also, new studies offer improved knowledge of these receptors' signalling pathways: mitogen-activated protein kinase signalling (MAPK) pathway and protein kinase B/phosphatidylinositol 3-kinase/mammalian target of rapamycin (AKT/PI3K/mTOR) pathway. AKT/ $\mathrm{PI3K} / \mathrm{mTOR}$ pathway, frequently altered in GB, also with mutation of PTEN gene, makes up for the complexity and heterogeneity of $G B$, making it one of the most rational targets in GB [7-9]. As a consequence of the last two decades of research in glioblastoma, a better understanding regarding the 
tumour's biology, mechanisms to evade apoptosis, and genetic profiling are defined now and are presented as clear targets for GB. Most importantly is the necessity of effective treatment for this aggressive malignancy, molecular therapy being one of the possible solutions.

\section{Tumour heterogeneity and angiogenesis in glioblastoma}

Angiogenesis is induced early in the stages of development of malignant tumours and is pathologically promoted by a multitude of genetic alterations [10, 11]. Characteristic for angiogenesis in glioblastoma is microvascular proliferation surrounding necrotic areas as a response to a hypoxic environment, which in turn increases the expression of angiogenic factors and their signalling pathways (RAS/RAF/ERK/MAPK pathway, PI3K/Akt signalling pathway and WTN signalling cascade) [12, 13]. Many in vitro and in vivo studies described and explained the importance of vascular endothelial growth factor (VEGF) system, platelet-derived growth factor (PDGF) system, fibroblast growth factor (FGF) system, insulin-like growth factor-1 (IGF-1) system, angiopoietins, and interleukins as pro-angiogenic factors in $G B[14,15]$. All signalling pathways emerging from these molecules (MAPK pathway, PI3K/Akt pathway, and WTN signalling cascade) maintain normal cell proliferation, metabolism, and survival; however, persistent activation of these pathways is correlated with cancer development. Overexpression of angiogenic tyrosine kinase receptors (TKR) is a main factor in the de- velopment of new vessels, and many modern molecular targeting therapies involve angiogenesis inhibition [16-18]. The various genetic alterations needed for development of primary and secondary glioblastoma and their interaction with tumour angiogenesis are illustrated in Figs. 1 and 2.

Genetic alterations are critical in developing glioblastoma multiforme, which proved to be a highly heterogeneous tumour. Genomic profiling has been able to differentiate between primary and secondary glioblastoma and identified four subtypes of glioblastoma characterised by different molecular and genetic alterations, all influencing tumour angiogenesis [19, 20].

Genetic expression pattern classifies glioblastoma in classical, mesenchymal, neural and proneural subtypes. Importantly, secondary glioblastoma is predominately formed by the proneural subtype. The first three subtypes described above are known to present IDH-wild type mutation; in contrast, proneural subtype appears to have a high frequency of IDH1/2 (isocitrate dehydrogenase) mutation. Histopathological differentiation was largely indistinguishable until IDH1/2 mutation was proposed for testing, making a definite diagnosis between secondary and primary glioblastoma. IDH1/2 mutation, a biomarker for secondary glioblastoma, is found to be positive in the majority of patients with this type of malignancy. Furthermore, the mutation is present in more than $80 \%$ of patients with diffuse and anaplastic astrocytomas, overall being correlated with better prognosis of the disease [2123]. IDH1/2 mutation along with PTEN mutation (phosphatase and tensin homolog) and EGFR overexpression con-

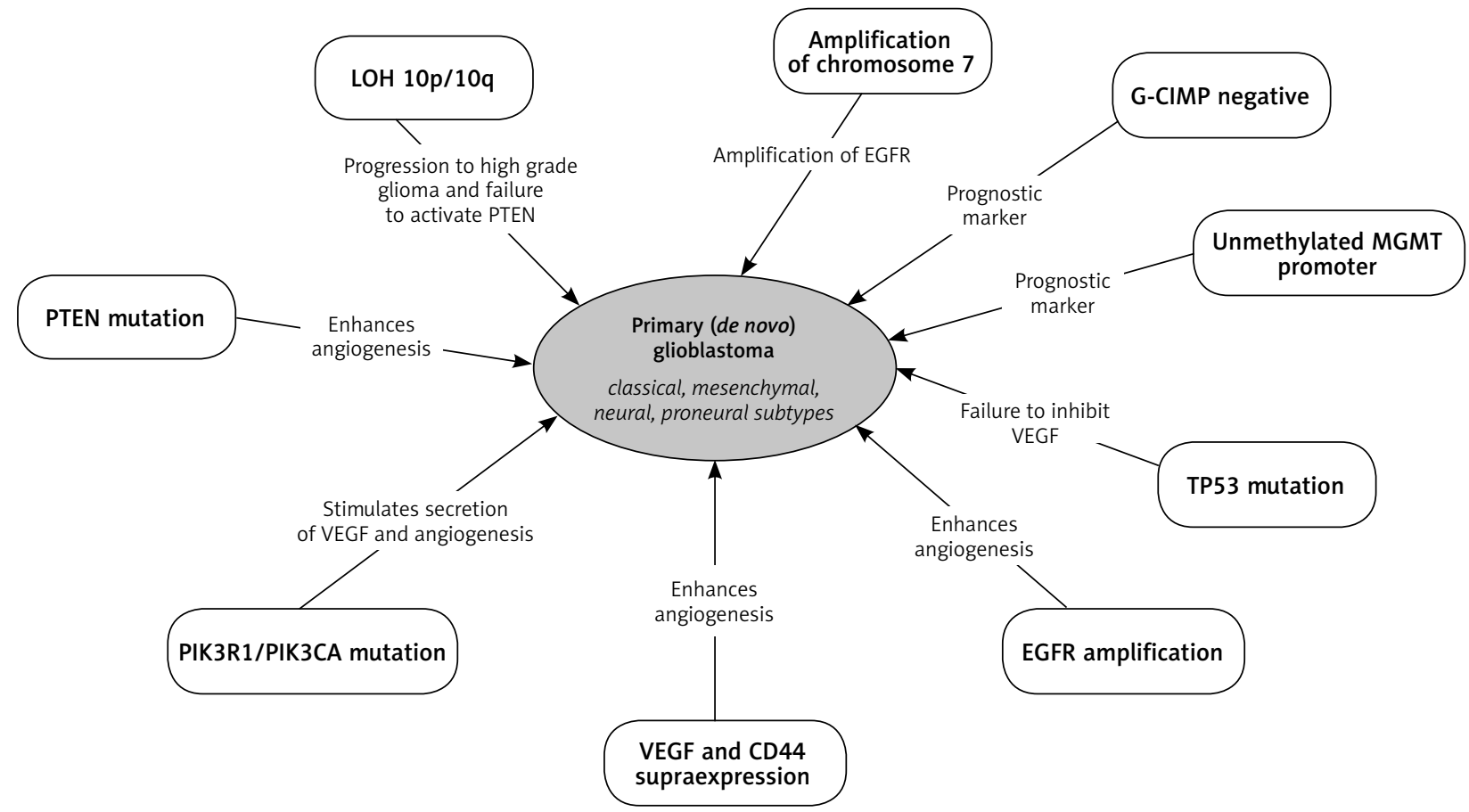

G-CIMP - CPG island methylation promoter phenotype; LOH 10p/10q-loss of heterozygosity of 10p/10q; PTEN-phosphatase and tensin homolog; VEGF-vascular endothelial growth factor; PIK3R1/PIK3CA - protein kinase B/phosphatidylinositol 3-kinase; TP53 - tumour protein p53; EGFR - epidermal growth factor receptor; MGMT-06-methylguanine-DNA methyltransferase

Fig. 1. Molecular and genetic alteration in primary glioblastoma development 


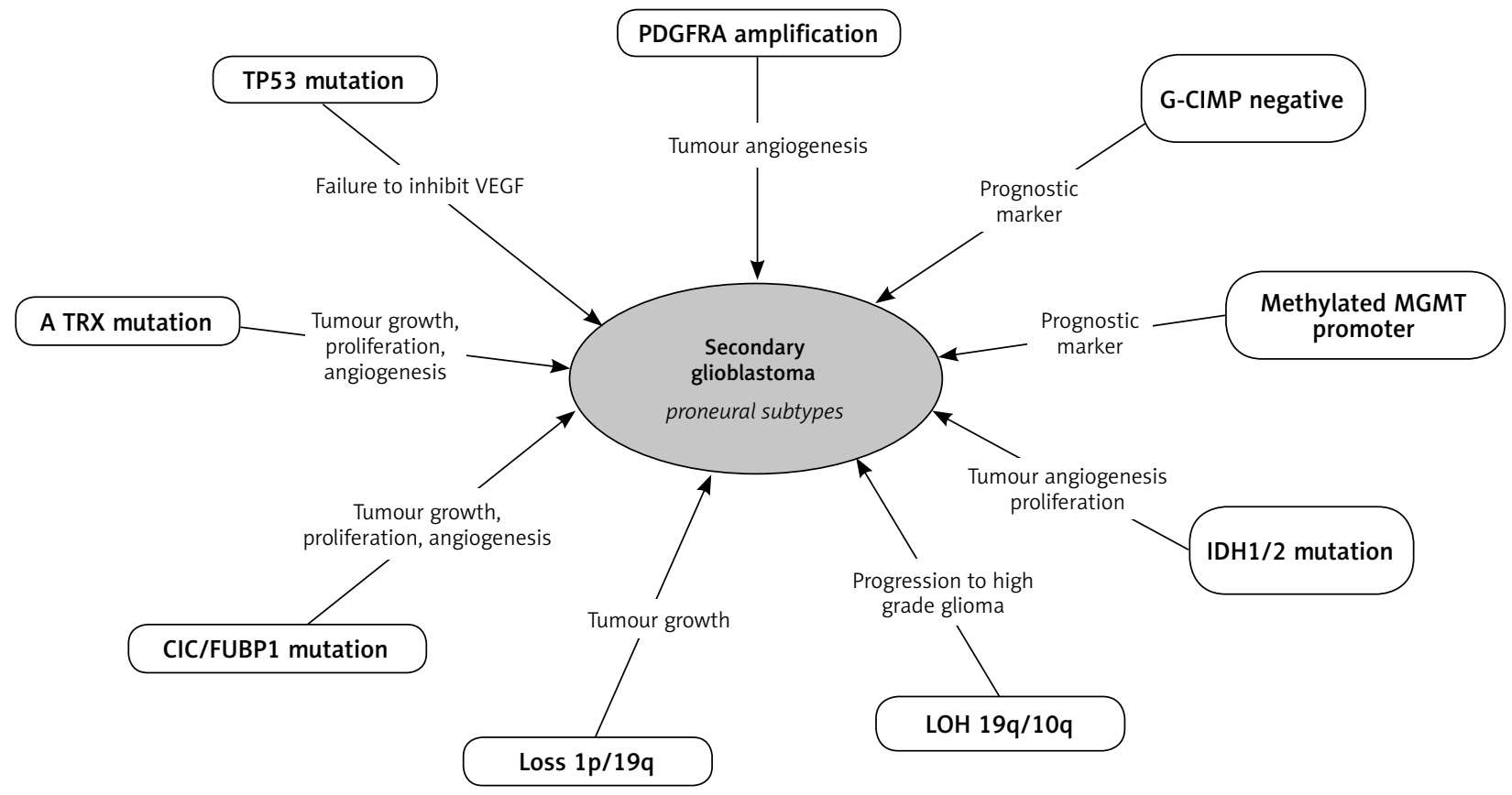

G-CIMP - CPG island methylation promoter phenotype; LOH 19q/10q-loss of heterozygosity of 19q/10q; TP53-tumour protein p53; MGMT - O6-methylguanine-DNA methyltransferase; IDH1/2 - isocitrate dehydrogenase 1/2; CIC/FUBP1 - homolog of Drosophila capicua/far-upstream binding protein 1; ATRX - $\alpha$-thalassemia/mental retardation syndrome X-linked; PDGFRA - platelet-derived growth factor receptor A; VEGF - vascular endothelial growth factor

Fig. 2. Molecular and genetic alteration in secondary glioblastoma development

tribute to stabilisation of HIF-1 $\alpha$ (hypoxia-inducible factor $1 \alpha$ ) switching to a proangiogenic phase by increasing transcription of VEGF. Non-VEGF pathways that induce angiogenesis in glioblastoma are PDGF, FGF systems, and direct interactions with surface tyrosine kinase receptors. Abnormalities in overexpression of VEGF, CD44, chitinase 3-like 1 (CHI3L1/YKL40), LGALS3 (lectin, galactoside-binding, soluble, 3) genes, TP53 mutations, PDGFRA amplification, PTEN mutation, ATRX mutation ( $\alpha$-thalassemia/mental retardation syndrome $X$-linked), loss of heterozygosity of $19 q / 10 q$ (LOH 19q/10q), loss of chromosome 1p/19q, CIC/FUBP1 (homolog of Drosophila capicua/far-upstream binding protein 1) mutation, potent regulators of cell growth, are key factors in the activation of pathologic cellular growth and aberrant angiogenic development [24]. Efforts to map the two different major types of glioblastoma provide not only a good diagnostic tool for prognostic and predictive biomarkers, but also for new and possibly personalised therapeutic targets for patients suffering from this malignancy. IDH1/2 mutation associated with ATRX mutation was significantly correlated with longer survival rates [25]. Moreover, recent observations after genetic profiling of glioblastoma contribute to a better prognosis for patients. One example is the good response to temozolomide and radiotherapy treatment in patients with glioblastoma with MGMT hypermethylation and IDH1/2 mutation [26]. A new study suggests the involvement of YKL40 in progression and drug resistance [27]. Tumour heterogeneity plays a key role in vascular response to treatment by activating secondary pathways for tumour angiogenesis, explaining why targeted therapies such as bevacizumab (a VEGF inhibitor) or cediranib (a potent VEGFR inhibitor) have such differing results in patients, some having poor response, others presenting with favourable response [28].

\section{Tyrosine kinase receptors and signalling pathways in glioblastoma angiogenesis}

In vivo studies reported three VEGFR receptors: VEGFR1 (Flt 1), VEGFR2 (Flk-1/KDR), and VEGFR3 (Flt4), all of them associated with tumour angiogenesis. VEGFR2, the main receptor of the VEGF system, has been reported to be important in GB angiogenesis, Flk1/KDR is present in endothelial cells, and recent research studies have described the secretion of VEGFR2 by GB cells. Flk1 intracellular signalling is mediated through activation of RAS/RAF/ERK/ MAPK and PI3K/Akt signalling pathways [29, 30]. The effector proteins are activated after receptor binding to $\mathrm{SH} 2$ domain like phospholipase C- $\delta$ (PLC $\delta$ ), usually known to be involved in VEGFR signalling. VEGFR2 activation triggers PI3K and phosphatidylinositol 3,4,5-triphosphate (PIP3), which in turn activates serine/threonine kinase Akt/PKB (protein kinase B). PI3K/Akt signalling pathway is involved in cell proliferation, cell survival, and endothelial cell migration [31-33]. Akt/PKB phosphorylation induces mTOR activation and apoptosis inhibition. mTOR pathway, through p70S6K (p70 ribosomal S6 protein kinase) and 4EBP1(4E-Binding Protein), is known to mediate numerous physiological and pathological processes in angiogenesis, as well as modulating malignant cell proliferation and survival. Akt/PKB also stimulates angiogenesis through endothelial nitric oxide synthesis (eNOS) [34, 35]. One study on GB cells reiterates the importance of PTEN mutation 
in PI3K/Akt pathway activation; loss of PTEN triggers the accumulation of PIP3 and Akt activation, which in turn inhibits mTOR pathway. VEGFR activates PLC $\delta$ and protein kinase C (PKC), which consecutively activates a series of kinases, including MEK and MAPK. PKC $\alpha$ and PKC $\beta$ are both involved in tumour progression. Supplementary PKC $\alpha$, a substrate for PI3K, has properties in modulating cell survival by pro-mitotic and anti-apoptotic actions [7, 15]. In contrast, PKC $\beta$ is directly involved in angiogenesis, by linking VEGFR2 and evading apoptosis through the interaction with PTEN/Akt. In a randomised clinical trial, one selective inhibitor $P K C \beta$ showed disappointing results, suggesting the presence of complex interconnections between PI3K/ Akt and other signalling pathways, as other compensatory pathways were activated. Tumour proliferation and clonogenicity was shown to be linked to overexpression of VEGFR2, which also seems to act independently of VEGF in $G B$ development $[36,37]$. More recently, the expression of VEGFR3 in glioblastomas and haemangioblastomas was also described.

The PDGF family (PDGF-AA, PDGF-AB, PDGF-BB, PDGFCC, PDGF-DD) have a common growth factor domain named PDGF/VEGF homology domain. Two PDGFRs were reported in the literature: PDGFR $\alpha$ and $\operatorname{PDGFR} \beta[14,38]$. PDGFR $\beta$ uses RAS/RAF/ERK/MAPK signalling pathway for tumour expansion by activating genetic mutations relating to DNA synthesis and mitosis. KRas protein expression occurs frequently in malignancies; however, new research suggests that KRas alone is not sufficient to induce glioblastoma genesis, additional activation of Raf-1, BRAF (serine/threonine-protein kinase B-Raf), ATRX mutation, and TP53 mutation is necessary for glioblastoma oncogenesis $[39,40]$. Alone, PDGFR expression acts more as a biomarker for cancer than as a pro-oncogene. PDGFR $\beta$ is mostly linked to cell motility and proliferation. Autophosphorylation of PDGFR leads to an association between various phosphorylated tyrosine residues, which in turn activate RAS/RAF/ERK/MAPK and PI3K/Akt signalling pathways as well as the signal transduction and transcription activator (STAT) pathway [34, 40, 41]. Some research studies suggest that the involvement of PDGFR in autocrine signalling pathways promotes cancer stem cells in glioblastoma [7, 42, 43].

Another relevant receptor for tumour angiogenesis and expansion is EGFR, which is activated in approximately $50 \%$ of primary glioblastomas. This receptor belongs to the ErbB family that consists of four human EGF receptors, Her1-4. The studies for endothelial growth factor receptor denoted a vast manner of pathway signalling: RAS/RAF/ ERK/MAPK and PI3K/AKT/mTOR signalling pathway, activation of Wnt/ $\beta$-catenin, Notch, and TGF- $\beta$ (transforming growth factor- $\beta$ ) extensively researched signal pathways $[44,45]$. EGFR activation by binding to the ligand activates various molecules like Grb (2 and 7), JAKs (Janus kinases), Src (c-Src tyrosine kinase), PI3K, phospholipase $C-\delta$, SH1, SH2, and STAT; RAS/MAPK signalling pathway, PI3K/AKT/ mTOR signalling pathway, after EGFR activation, modulate cell proliferation, differentiation, and survival [41, 46]; JAK/ STAT, STAT1, STA3 or JAK-independent activation trigger on transcription factors such as c-jun, c-fos, jun B and c-Myc.
EGFR also interacts with Wnt/ $\beta$-catenin pathway at various points. Wnt/ $\beta$-catenin pathway plays a significant role in the survival of several types of tumour cells, including brain tumours, making this pathway, in recent years, an important target for glioblastoma therapy. In cancer, interaction of Wnt and Frizzled/lipoprotein-receptor related protein ( $\mathrm{Fzd}$ ) generates the formation of the Dvl-Fzd complex (Dishevelled-Frizzled complex) that inactivates regulatory mechanisms including leukocyte enhance factor-1 (LEF-1) or T cell factors (TCF). TGF- $\beta$ is frequently upregulated in glioblastoma, acting through the Smad (Mad-homologues, MADH) transcription factors family and receptor-regulated Smads (R-Smad). TGF- $\beta$ pathway is implicated in glioma invasiveness and migration. Notch pathway is fundamental to normal development, and its deregulation is involved in tumour angiogenesis, cell proliferation, and apoptosis. EGFR is able to modulate both TGF- $\beta$ and Notch pathways, the latter being influenced in a smaller proportion by VEGFR [5, 47-49]. Tumour apoptosis is induced by the selective inhibitors of angiogenesis, tumour proliferation, and inhibition of pathways signalling and is facilitated by activation of caspase cascade (cysteinyl aspartate proteinases) [50].

FGFR, activated by FGF ligand, modulates a series of processes, including cell proliferation and cell migration. Through GAB1 (GRB2-associated binding protein 1), SOS1 (Son of sevenless homolog 1), SHC1 (Src homology 2 domain containing transforming protein 1) and Grb2 domains FGF1-FGFR activates RAS/RAF/ERK/MAPK signalling pathway. New evidence shows that FGFR is involved in a number of pro-oncogenic processes in GB such as tumour invasion and proliferation, being correlated with a poor prognostic in patients with GB [51]. PI3K/AKT/mTOR signalling pathway activation by FGFR is important in cell survival and angiogenesis; a recent study strongly related their ligand, FGF2, as a prognostic biomarker, to the proneural type of glioblastoma [8]. FGF1-FGFR also activates other pathways such as Jnk/p38 Mapk and STAT3/ NF-кB, with crucial implications in neurogenesis, apoptosis, cell proliferation, and invasion [52]. VEGF and FGF autocrine feedback loop has been shown to increase supra-activation of their cognate receptors and mediate tumour growth. A schematic overview of different signalling pathways involved in tumour cell proliferation, migration, and survival is depicted in Fig. 3.

\section{Drug development in glioblastoma}

The new molecular targeted therapies focus on the angiogenic TRKs and their signalling pathways inactivation. In 2009, the Food and Drug Administration (FDA) approved bevacizumab (Avastin), the first drug from the emerging class of new molecular therapy, as a second-line treatment of recurrent glioblastoma. Bevacizumab is also used as a VEGF inhibitor in other types of neoplasm: breast, lung, and colon [53, 54]. Nowadays, more molecular-specific drugs are being evaluated in clinical studies: cediranib, a potent VEGFR inhibitor (REGAL trial), sunitinib (Sutent), a multikinase inhibitor for VEGFR, PDGFR, c-Kit (tyrosine-protein-kinase KIT), sorafenib (Nexaver), and a multikinase inhibitor for VEGFR, PDGR, c-Kit, and for 


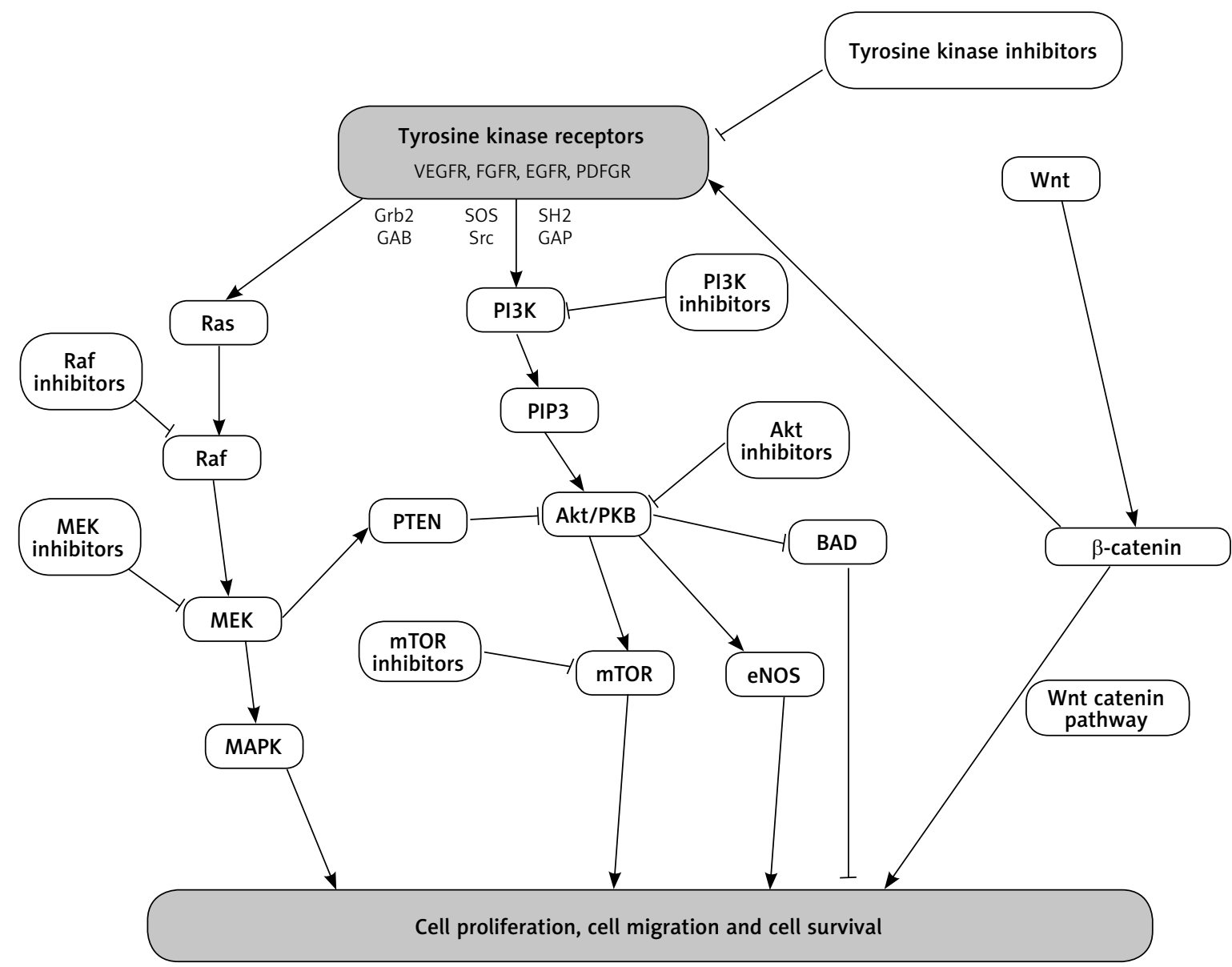

Fig. 3. Tyrosine kinase receptors and their signalling pathways involved in angiogenesis. Wnt catenin pathway stimulates tyrosine kinase receptors (TKRs) activation. RAS/RAF/ERK/MAPK and PI3K/Akt signalling pathways activation can produce a variety of processes involved in angiogenesis like cell proliferation, migration and survival. eNos (endothelial nitric oxide synthase) influenced by AKT/PKB promotes vascular permeability. MEK stimulates PTEN (phosphatase and tensin homolog) inhibiting protein kinase B (PKB). BAD (Bcl-2-associated death promoter); Potential therapeutic targets are specified

RAS/RAF/ERK/MAPK signalling pathway [55-57]. Despite the new advances in drug discovery, the majority of newly targeted therapies are still in clinical trial phase, weather alone or in combination with standard chemotherapeutics (temozolomide, carboplatin, cisplatin, lomustine) or radiotherapy $[37,58]$. A novel discovery is the better outcome of patients with hypermethylation of $\mathrm{O}^{6}$-methylguanine-DNA methyltransferase (MGMT) gene promoter, presently believed to confer tumour chemosensitivity. MGMT gene promoter has been described in approximately $50 \%$ of glioblastoma multiforme.

VEGF system remains an important target for the new molecular therapies. One example is VEGF Trap (aflibercept), acting as competitive VEGF-A isoforms binding to VEGFR1/2, with good effect on tumour cells but high host toxicity [59]; the capacity of VEGFR to act independently in $G B$ has changed the perspective in GB treatment, making the receptors TKR a more rationale target. VEGFR2 inhibitors, such as Angiocept (CT-322), showed promising results in a phase I clinical trial [60]. BEZ 235, a dual PI3K/mTOR inhibitor, had favourable outcomes in a phase I and II clinical trial, being well tolerated in patients with solid tumour and prolonging the patients' survival [61, 62]. Apoptosis in cancer cells treated with BEZ235 is mediated through extrinsic pathway by activation of TNF-R1 (ligand-activated tumour-necrosis factor receptor-1), FAS (Apo-1), DR4/DR5 (TRAIL receptors 1/2) that bind TNF $\alpha$, CD95, and tumour necrosis factor-related apoptosis inducing factor (TRAIL) and activates caspase cascade through caspase 2 . One in vitro study showed that responders to dual PI3K/mTOR inhibitor contained EGFR amplification or PI3K mutation [63]. Conversely, drug resistance is one of the major causes for failure of response to treatment, and it seems that ERK pathway activation is one of the main factors of drug resistance $[64,65]$. Another dual PI3K/mTOR inhibitor, XL 765 , acts by inhibition of phosphorylation of multiple PI3K/ phosphatase pathways proteins [66]. Congruent results were found in one study involving a PI3K/AKT inhibitor, BKM120 [67]. Despite unsure results in a phase I clinical trial for XL 765 due to adverse effects on liver function, an interesting phenomenon was the lack of apoptosis induction through caspase cascade; the antiproliferative property was associated with G1 phase specific block [68]. An important problem in therapy failure is the continuous ability 
Table 1. Molecular therapy currently in preclinical and clinical development

\begin{tabular}{|c|c|c|c|}
\hline Agent & Mechanism of action & Phase development in glioblastoma & Indication for other cancers \\
\hline $\begin{array}{l}\text { Cetuximab } \\
{[70]}\end{array}$ & EGFR & phase II trial in patients with recurrent GB & colon cancer \\
\hline $\begin{array}{l}\text { Erlotinib } \\
{[71,72]}\end{array}$ & EGFR & $\begin{array}{l}\text { phase II trial in patients with newly diagnosed GB; } \\
\text { phase I/II trial in patients with recurrent diagnosed GB } \\
\text { in combination with temsirolimus }\end{array}$ & $\begin{array}{l}\text { NSCLC, } \\
\text { pancreatic cancer }\end{array}$ \\
\hline $\begin{array}{l}\text { Nimotuzumab } \\
{[73]}\end{array}$ & EGFR & phase III trial in patients with newly diagnosed GB & pancreatic cancer \\
\hline $\begin{array}{l}\text { Angiocept (CT-322) } \\
{[74]}\end{array}$ & VEGFR-2 & $\begin{array}{l}\text { phase II trial in patients with recurrent diagnosed GB } \\
\text { (insufficient efficacy) }\end{array}$ & solid tumours \\
\hline $\begin{array}{l}\text { ABT-414 } \\
{[75]}\end{array}$ & $\begin{array}{l}\text { active EGFR or } \\
\text { mutant EGFRvIII }\end{array}$ & phase I trial in patients with recurrent unresectable GB & $\begin{array}{l}\text { solid tumours, NSCLC, prostate } \\
\text { cancer, colorectal cancer }\end{array}$ \\
\hline $\begin{array}{l}\text { Gefitinib } \\
{[76]}\end{array}$ & EGFR & $\begin{array}{l}\text { phase } I / I I \text { trial in patients with newly diagnosed GB in } \\
\text { combination with radiation therapy }\end{array}$ & $\begin{array}{l}\text { advanced or metastatic NSCLC, } \\
\text { breast cancer }\end{array}$ \\
\hline $\begin{array}{l}\text { Aflibercept } \\
\text { [77] }\end{array}$ & anti-VEGF & phase II trial in patients with recurrent diagnosed GB & metastatic colorectal cancer \\
\hline $\begin{array}{l}\text { Vatalanib } \\
{[78]}\end{array}$ & $\begin{array}{l}\text { VEGFR, PDGFR, and } \\
\text { C-KIT }\end{array}$ & $\begin{array}{l}\text { phase I trial in patients with newly diagnosed GB in } \\
\text { combination with standard therapy }\end{array}$ & metastatic colorectal cancer \\
\hline $\begin{array}{l}\text { Dasatinib } \\
{[79]}\end{array}$ & $\begin{array}{l}\text { SRC, C-KIT, EPHA2, } \\
\text { and PDGFR }\end{array}$ & phase II trial in patients with recurrent GB & $C M L, A L L$ \\
\hline $\begin{array}{l}\text { Sunitinib } \\
{[80]}\end{array}$ & $\begin{array}{l}\text { VEGFR 2, PDGFR, } \\
\text { c-KIT, FLT3 }\end{array}$ & phase II trial in patients with recurrent GB & $\begin{array}{l}\text { gastrointestinal tumour, renal cell } \\
\text { carcinoma }\end{array}$ \\
\hline $\begin{array}{l}\text { Sorafenib } \\
{[81,82]}\end{array}$ & $\begin{array}{l}\text { VEGFR } 1-2, \text { PDGFR } \\
\alpha-\beta, \text { c-KIT, FLT3, and } \\
\text { RET }\end{array}$ & $\begin{array}{l}\text { phase I trial in patients with newly diagnosed GB in } \\
\text { combination with standard therapy; } \\
\text { phase II trial in patients with recurrent GB }\end{array}$ & $\begin{array}{l}\text { renal cell carcinoma, renal } \\
\text { tumours, hepatocellular carcinoma }\end{array}$ \\
\hline $\begin{array}{l}\text { Motesanib } \\
{[83]}\end{array}$ & VEGFR, PDGFR, c-KIT & - & NSCLC \\
\hline $\begin{array}{l}\text { Vandetanib } \\
{[84,85]}\end{array}$ & $\begin{array}{l}\text { VEGFR2, EGFR, and } \\
\text { RET }\end{array}$ & $\begin{array}{l}\text { phase II trial in patients with newly diagnosed GB and } \\
\text { phase I/II trial in patients with recurrent GB }\end{array}$ & thyroid cancer, NSCLC \\
\hline $\begin{array}{l}\text { Pazopanib } \\
\text { [86] }\end{array}$ & $\begin{array}{l}\text { VEGFR-1-2 -3, PDGFR } \\
\alpha-\beta, c-K I T\end{array}$ & phase II trial in patients with recurrent GB & renal tumour, sarcoma \\
\hline $\begin{array}{l}\text { Bosutinib } \\
\text { [87] }\end{array}$ & Src and $A B L$ & phase II trial in patients with recurrent GB & \\
\hline $\begin{array}{l}\text { Nilotinib } \\
{[88]}\end{array}$ & $\begin{array}{l}\text { ABL1/BCR-ABL1 and } \\
\text { KIT, PDGFR }\end{array}$ & - & $\begin{array}{l}\text { metastatic gastrointestinal } \\
\text { stromal tumours }\end{array}$ \\
\hline $\begin{array}{l}\text { Axitinib } \\
\text { [89] }\end{array}$ & VEGFR-1, $-2,-3$ & proved efficient in preclinical models of glioblastoma & melanoma, NSCLC \\
\hline $\begin{array}{l}\text { Bez } 235 \\
{[90]}\end{array}$ & $\mathrm{PI3K} / \mathrm{mTOR}$ & proved efficient in preclinical models of glioblastoma & $\begin{array}{l}\text { solid tumours, metastatic breast } \\
\text { cancer }\end{array}$ \\
\hline $\begin{array}{l}\text { Everolimus } \\
\text { [91] }\end{array}$ & mTOR & $\begin{array}{l}\text { phase II trial in patients with newly diagnosed GB in } \\
\text { combination with standard therapy }\end{array}$ & $\begin{array}{l}\text { renal cell carcinoma, lymphoma, } \\
\text { hepatocellular carcinoma }\end{array}$ \\
\hline $\begin{array}{l}\text { Temsirolimus } \\
{[72,92]}\end{array}$ & mTOR & $\begin{array}{l}\text { phase II trial in patients with recurrent GB in } \\
\text { combination with bevacizumab; } \\
\text { phase I/II trial in patients with recurrent diagnosed GB } \\
\text { in combination with erlotinib }\end{array}$ & $\begin{array}{l}\text { solid tumours, haematological } \\
\text { malignancies }\end{array}$ \\
\hline $\begin{array}{l}\text { BKM120 } \\
{[93]}\end{array}$ & PI3K/Akt & proved efficient in in vitro models of glioblastoma & $\begin{array}{l}\text { solid tumours, NSCLC, prostate } \\
\text { cancer, colorectal cancer, } \\
\text { haematological malignancies }\end{array}$ \\
\hline $\begin{array}{l}X L 184 \\
{[94]}\end{array}$ & $\begin{array}{l}\text { MET, VEGFR-2 and } \\
\text { RET, KIT }\end{array}$ & phase II trial in patients with progressive/recurrent GB & medullary thyroid cancer, NSCLC \\
\hline $\begin{array}{l}X L 765 \\
{[68]}\end{array}$ & $\mathrm{PI} 3 \mathrm{~K}, \mathrm{mTOR}$ & phase I trial in patients with recurrent/GB & solid tumours, NSCLC \\
\hline $\begin{array}{l}\text { SF } 1126 \\
{[95]}\end{array}$ & $\mathrm{PI} 3 \mathrm{~K}, \mathrm{mTOR}$ & proved efficient in preclinical models of glioblastoma & solid tumours \\
\hline
\end{tabular}


Table 1. Cont.

\begin{tabular}{|c|c|c|c|}
\hline $\begin{array}{l}\text { PF } 4691502 \\
{[96]}\end{array}$ & PI3K, mTOR & proved efficient in in vitro models of glioblastoma & $\begin{array}{l}\text { colorectal cancer, breast and } \\
\text { gastric cancer }\end{array}$ \\
\hline $\begin{array}{l}\text { Perifosine } \\
(\text { KRX-0401) } \\
{[97]}\end{array}$ & AKT & $\begin{array}{l}\text { phase I/II trial in patients with recurrent GB; } \\
\text { phase II trial in patients with recurrent GB in } \\
\text { combination with temsirolimus (ongoing) }\end{array}$ & $\begin{array}{l}\text { colorectal cancer, MM, NSCLC, } \\
\text { renal cell carcinoma, } \\
\text { ovarian cancer and } \\
\text { haematological malignancies }\end{array}$ \\
\hline $\begin{array}{l}\text { AZD } 2014 \\
{[98]}\end{array}$ & mTOR & $\begin{array}{l}\text { proved efficient in in vitro models of glioblastoma } \\
\text { stem like cells enhances radiosensitivity }\end{array}$ & solid tumours \\
\hline $\begin{array}{l}\text { Celgene }(C C-223) \\
{[99]}\end{array}$ & mTOR & proved efficient in preclinical models of glioblastoma & NHL and MM \\
\hline $\begin{array}{l}\text { INK } 128 \\
{[100]}\end{array}$ & mTOR & recruiting phase in patients with recurrent GB & NHL, MM, solid tumours \\
\hline
\end{tabular}

of the tumour to develop drug resistance mechanisms, observed after new molecular targeted therapy in many phase II/III clinical trials. Evolving theories are stating the importance of tumour heterogeneity and its correlation with angiogenesis, which are important factors for continuum disease progression and evasion from new targeted therapies in glioblastoma. Table 1 highlights the different development phases for small molecular targeted drugs in glioblastoma [16, 29, 35, 69-100].

Several signalling pathway inhibitors, such as mTOR inhibitors everolimus and temsirolimus, showed dissatisfactory results in clinical trials, in part due to rapid progression of drug resistance [101]. Everolimus, a specific inhibitor of mTOR, is known to activate compensatory pathways, although favourable results were depicted in a few preclinical and clinical studies when used in combination with bendamustine or radiotherapy. Apoptosis pathways are activated through PI3K/AKT/PKB system downstream inducing phosphorylation of $\mathrm{mTOR}$, not blocked by specific mTOR inhibitors $[102,103]$. Perifosine (KRX-0401), an AKT pathway inhibitor, was found to induce cytotoxicity and evade drug resistance in a study regarding myeloma. Inhibition of AKT through activation of anti-apoptotic signals is one response for obtaining drug efficacy. Another response is activation of JNK (c-Jun N-terminal kinases) pathway, which is a known byway implicated in cellular apoptosis [104, 105]. Increasing the perifosine concentration was demonstrated to have an amplified effect on cellular apoptosis. Apoptosis in correlation with treatment occurs through caspase cascade, particularly through caspase-3 and -9 [106].

Limited clinical benefit was reported after forerlotinib, gefitinib, or cetuximab in recurrent or primary glioblastoma, either as monotherapy or in combination with other treatment approaches for glioblastoma. Multi-targeted inhibitor drugs are expected to be more effective compared to those that inactivate a single receptor. One example is the case of sorafenib, a multikinase inhibitor, with consistently good outcomes in clinical trials $[107,108]$. Sorafenib induces apoptosis by targeting Mcl-1 protein, an antiapoptotic member of BCL2 family, in turn reducing cell viability. [109]. Similarly dasatinib, a SRC inhibitor (proto-oncogene tyrosine-protein kinase), known as an inhibitor of Bcr-Abl tyrosine kinase), has promising results by inhibiting cell invasion, sustaining apoptosis and tumour regression in glioblastomas and other malignant diseases. Apoptosis is induced by downregulation of PI3K/AKT and STAT3, which act by compromising PTEN function and Src inhibition. Loss of both PTEN and p53 induces primary glioblastoma, with devastating pathological and clinical effects. In vitro studies with dasatinib showed efficacy of apoptosis on EGFR-mutant cells sensitive to gefitinib, but with minimal effect on WT EGFR cells [110]. Dasatinib has an inhibitory effect also on PDGFR and c-Kit [111]. Disappointing results were also obtained in a clinical trial for glioblastoma patients with the multi-kinase inhibitor imatinib, a PDGFR, $\mathrm{KIT}$, and ABL-kinase inhibitor, despite the success obtained in treating certain types of leukaemia [112]. Significant evidence of drug resistance mechanism is MET (MET proto-oncogene, receptor tyrosine kinase) amplification, detected after treatment with various tyrosine kinase inhibitors such as erlotinib, gefitinib, and imatinib. MET amplification is frequently associated with poor prognosis considering several biologic processes that initiate invasive growth. MET activation is induced by a hypoxic state, producing a high sensitivity to HGF (hepatocyte growth factor), activating RAS/ MAPK, PI3K/AKT and STAT3 pathways that will induce the so-called "invasive switch" [113, 114].

Based on the genetic and molecular pathology of glioblastoma, researchers provided new insight in treating this disease. EGFR amplification and PTEN mutation are known to induce drug resistance after treatment with EGFR inhibitors [115]. The pathological EGFR expression in glioblastoma is proposed to activate all intracellular mitogenic signalling (PI3K/AKT/mTOR, Raf/MEK/ERK, and Src/ STAT pathways) by interacting not only through Grb, JAKs, Src, PI3K, phospholipase $\mathrm{C}-\delta, \mathrm{SH} 1, \mathrm{SH} 2$, and STAT but also through ErbB2 and ErB3 transactivation [35, 65].

\section{Conclusions and perspectives}

Researchers have observed that GB tumours are different in many aspects, even when they derive from the same tissue, providing a reason for personalised therapy. An understanding of the molecular mechanisms regulating GB angiogenesis and invasion may be important in development of curative therapeutic approaches for the treatment of this devastating disease. 
The authors declare no conflict of interest.

The research is financed by: "Program of Excellence in multidisciplinary doctoral and postdoctoral research in chronic diseases", Contract No. POSDRU/159/1.5/S/133377, co-financed project from the European Social Fund by Operational Sectoral Programme Human Resources Development 2007-2013 and PN-II-ID-PCE-2011-3-1041 UEFISCDI, Romania.

\section{References}

1. Dunn GP, Rinne ML, Wykosky J, et al. Emerging insights into the molecular and cellular basis of glioblastoma. Genes Dev 2012; 26: 756-84.

2. Ahmed R, Oborski MJ, Hwang M, Lieberman FS, Mountz JM. Malignant gliomas: current perspectives in diagnosis, treatment, and early response assessment using advanced quantitative imaging methods. Cancer Manag Res 2014; 6: 149-70.

3. Ostrom QT, Gittleman H, Farah P, Ondracek A, Chen Y, Wolinsky Y, et al. CBTRUS statistical report: Primary Brain and central nervous system tumors diagnosed in the United States in 2006-2010. Neuro Oncol 2013; 15 (Suppl 2): ii1-56.

4. Baker GJ, Yadav VN, Motsch S, Koschmann C, Calinescu A-A, Mineharu $Y$, et al. Mechanisms of glioma formation: iterative perivascular glioma growth and invasion leads to tumor progression, VEGF-independent vascularization, and resistance to antiangiogenic therapy. Neoplasia 2014; 16: 543-61.

5. Hardee ME, Zagzag D. Mechanisms of glioma-associated neovascularization. Am J Pathol 2012; 181: 1126-41.

6. Hanahan D, Weinberg RA. Hallmarks of Cancer: The Next Generation. Cell 2011; 144: 646-74.

7. McNamara MG, Sahebjam S, Mason WP. Emerging Biomarkers in Glioblastoma. Cancers 2013; 5: 1103-19.

8. Sooman L, Freyhult E, Jaiswal A, et al. FGF2 as a potential prognostic biomarker for proneuralglioma patients. Acta Oncol Stockh Swed 2015; 54: 385-94.

9. Walker C, Baborie A, Crooks D, Wilkins S, Jenkinson MD. Biology, genetics and imaging of glial cell tumours. Br J Radiol 2011; 84 (Spec Issue 2): S090-106.

10. Raica M, Cimpean AM, Ribatti D. Angiogenesis in pre-malignant conditions. Eur J Cancer Oxf Engl 2009; 45: 1924-34.

11. Rodriguez FJ, Orr BA, Ligon KL, Eberhart CG. Neoplastic cells are a rare component in human glioblastoma microvasculature. Oncotarget 2012; 3: 98-106.

12. Poleszczuk J, Hahnfeldt P, Enderling H. Therapeutic implications from sensitivity analysis of tumor angiogenesis models. PLoS One 2015; 10: e0120007.

13. Kesari S. Understanding glioblastoma tumor biology: the potential to improve current diagnosis and treatments. Semin Oncol 2011; 38 Suppl 4: S2-10.

14. Puputti M, Tynninen O, Sihto $\mathrm{H}$, et al. Amplification of KIT, PDG FRA, VEGFR2, and EGFR in gliomas. Mol Cancer Res MCR 2006; 4: 927-34.

15. Koch S, Claesson-Welsh L. Signal transduction by vascular endothelial growth factor receptors. Cold Spring Harb Perspect Med 2012; 2(7): a006502.

16. Gotink KJ, Verheul HMW. Anti-angiogenic tyrosine kinase inhibitors: what is their mechanism of action? Angiogenesis 2010; 13: $1-14$.

17. Lin MI, Sessa WC. Antiangiogenic therapy: Creating a unique "window" of opportunity. Cancer Cell 2004; 6: 529-31.

18. Onishi M, Kurozumi K, Ichikawa T, Date I. Mechanisms of tumor development and anti-angiogenic therapy in glioblastoma multiforme. Neurol Med Chir (Tokyo) 2013; 53: 755-63.

19. Karcher S, Steiner H-H, Ahmadi R, Zoubaa S, Vasvari G, Unterberg A, Herold-Mende C. Different angiogenic phenotypes in primary and secondary glioblastomas. Int J Cancer 2006; 118: 2182-9.
20. Ohgaki H, Kleihues P. The definition of primary and secondary glioblastoma. Clin Cancer Res. 2013; 19: 764-72.

21. Horbinski C. What do we know about IDH1/2 mutations so far, and how do we use it? Acta Neuropathol (Berl) 2013; 125: 621-36.

22. Verhaak RGW, Hoadley KA, Purdom E, et al. An integrated genomic analysis identifies clinically relevant subtypes of glioblastoma characterized by abnormalities in PDGFRA, IDH1, EGFR and NF1. Cancer Cell 2010; 17: 98.

23. Clarke J, Penas C, Pastori C, et al. Epigenetic pathways and glioblastoma treatment. Epigenetics 2013; 8: 785-95.

24. Li R, Li H, Yan W, et al. Genetic and clinical characteristics of primary and secondary glioblastoma is associated with differential molecular subtype distribution. Oncotarget 2015; 6: 7318-24.

25. Jiao Y, Killela PJ, Reitman ZJ, et al. Frequent ATRX, CIC, FUBP1 and IDH1 mutations refine the classification of malignant gliomas. Oncotarget 2012; 3: 709-22.

26. Weller M, Stupp R, Reifenberger G, et al. MGMT promoter methylation in malignant gliomas: ready for personalized medicine? Nat Rev Neurol 2010; 6: 39-51.

27. Batista KMP, Vega IF, Eulate-Beramendi SA de, et al. Original article Prognostic significance of the markers IDH1 and YKL4O related to the subventricular zone. Folia Neuropathol 2015; 1: 52-9.

28. Batchelor TT, Sorensen AG, di Tomaso E, et al. AZD2171, a PanVEGF receptor tyrosine kinase inhibitor, normalizes tumor vasculature and alleviates edema in glioblastoma patients. Cancer Cell 2007; 11: 83-95.

29. Shibuya M. Vascular endothelial growth factor (VEGF) and its receptor (VEGFR) signaling in angiogenesis: a crucial target for antiand pro-angiogenic therapies. Genes Cancer 2011; 2: 1097-105.

30. Matsumoto T, Claesson-Welsh L. VEGF receptor signal transduc tion. Sci STKE Signal Transduct Knowl Environ 2001; 2001 (112): re21.

31. Wang L, Chen L, Wang Q, et al. Circulating endothelial progenitor cells are involved in VEGFR-2-related endothelial differentiation in glioma. Oncol Rep 2014: 32: 2007-14.

32. Fruman DA, Rommel C. PI3K and cancer: lessons, challenges and opportunities. Nat Rev Drug Discov 2014; 13: 140-56.

33. Xu C, Wu X, Zhu J. VEGF promotes proliferation of human glioblastoma multiforme stem-like cells through VEGF receptor 2 . Sci World Journal 2013; 2013: 417413.

34. Mellinghoff IK, Schultz N, Mischel PS, Cloughesy TF. Will kinase inhibitors make it as glioblastoma drugs? Curr Top Microbiol Immunol 2012; 355: 135-69.

35. McCubrey JA, Steelman LS, Chappell WH, et al. Ras/Raf/MEK/ERK and PI3K/PTEN/Akt/mTOR Cascade inhibitors: how mutations can result in therapy resistance and how to overcome resistance. Oncotarget 2012; 3: 1068-111.

36. Logue JS, Morrison DK. Complexity in the signaling network: insights from the use of targeted inhibitors in cancer therapy. Genes Dev 2012; 26: 641-50.

37. Bai R-Y, Staedtke V, Riggins GJ. Molecular targeting of glioblastoma: drug discovery and therapies. Trends Mol Med 2011; 17: 30112.

38. Cao Y. Multifarious functions of PDGFs and PDGFRs in tumor growth and metastasis. Trends Mol Med 2013; 19: 460-73.

39. Zhang J, Chen T, Mao O, et al. PDGFR- $\beta$-activated ACK1-AKT signaling promotes glioma tumorigenesis. Int J Cancer J Int Cancer 2015; 136: 1769-80.

40. Westermark B. Platelet-derived growth factor in glioblastomadriver or biomarker? Ups J Med Sci 2014; 119: 298-305.

41. Vogt PK, Hart JR. PI3K and STAT3: a New Alliance. Cancer Discov 2011; 1: 481-6.

42. Wilson TA, Karajannis MA, Harter DH. Glioblastoma multiforme: State of the art and future therapeutics. Surg Neurol Int 2014; 5: 64.

43. Liu K-W, Hu B, Cheng S-Y. Platelet-derived growth factor receptor alpha in glioma: a bad seed. Chin J Cancer 2011; 30: 590-602.

44. Paul I, Bhattacharya S, Chatterjee A, Ghosh MK. Current understanding on EGFR and Wnt/ $\beta$-catenin signaling in glioma and their possible crosstalk. Genes Cancer 2013; 4: 427-46.

45. Ferrari G, Cook BD, Terushkin V, Pintucci G, Mignatti P. Transforming growth factor-beta 1 (TGF- $\beta 1$ ) induces angiogenesis through 
vascular endothelial growth factor (VEGF)-mediated apoptosis. J Cell Physiol 2009; 219: 449-58.

46. Seshacharyulu P, Ponnusamy MP, Haridas D, Jain M, Ganti A, Batra SK. Targeting the EGFR signaling pathway in cancer therapy. Expert Opin Ther Targets 2012; 16: 15-31.

47. MacDonald BT, He X. Frizzled and LRP5/6 receptors for Wnt/ $\beta$-catenin signaling. Cold Spring Harb Perspect Biol 2012; 4(12).pii: a007880.

48. Xing Z-Y, Sun L-G, Guo W-J. Elevated expression of Notch-1 and EGFR induced apoptosis in glioblastomamultiforme patients. Clin Neurol Neurosurg 2015; 131: 54-8.

49. Guo S, Liu M, Gonzalez-Perez RR. Role of Notch and its oncogenic signaling crosstalk in breast cancer. Biochim Biophys Acta 2011; 1815: 197-213.

50. Van Meir EG, Hadjipanayis CG, Norden AD, Shu H-K, Wen PY, Olson JJ. Exciting new advances in neuro-oncology. CA Cancer J Clin 2010; 60: 166-93.

51. Katoh M, Nakagama H. FGF receptors: cancer biology and therapeutics. Med Res Rev 2014; 34: 280-300.

52. Raju R, Palapetta SM, Sandhya VK, et al. A network map of FGF-1/ FGFR signaling system. J Signal Transduct 2014; 2014: 962962.

53. Chinot OL, de La Motte Rouge T, Moore N, et al. AVAglio: Phase 3 trial of bevacizumab plus temozolomide and radiotherapy in newly diagnosed glioblastomamultiforme. Adv Ther 2011; 28: 334-40.

54. Narita Y. Drug review: safety and efficacy of bevacizumab for glioblastoma and other brain tumors. Jpn J Clin Oncol 2013; 43: 587-95.

55. Hu J, Kesari S. The molecular basis for novel therapies. Cancer J Sudbury Mass 2012; 18(1): 32-9.

56. Zhou J, Atsina K-B, Himes BT, Strohbehn GW, Saltzman WM. Novel delivery strategies for glioblastoma. Cancer J 2012; 18: 89-99.

57. Serova M, de Gramont A, Tijeras-Raballand A, Dos Santos C, Riveiro ME, Slimane K, Faivre S, Raymond E. Benchmarking effects of mTOR, PI3K, and dual PI3K/mTOR inhibitors in hepatocellular and renal cell carcinoma models developing resistance to sunitinib and sorafenib. Cancer Chemother Pharmacol 2013; 71: 1297 307.

58. Joshi AD, Loilome W, Siu I-M, Tyler B, Gallia GL, Riggins GJ. Evaluation of Tyrosine kinase inhibitor combinations for glioblastoma therapy. PLoS ONE 2012; 7: e44372.

59. Lockhart AC, Rothenberg ML, Dupont J, et al. Phase I study of intravenous vascular endothelial growth factor trap, aflibercept, in patients with advanced solid tumors. J Clin Oncol 2010; 28: $207-$ 14.

60. Tolcher AW, Sweeney CJ, Papadopoulos K, et al. Phase I and pharmacokinetic study of CT-322 (BMS-844203), a targeted adnectin inhibitor of VEGFR-2 based on a domain of human fibronectin. Clin Cancer Res 2011; 17: 363-71.

61. Wen PY, Lee EQ, Reardon DA, Ligon KL, Alfred Yung WK. Current clinical development of PI3K pathway inhibitors in glioblastoma. Neuro Oncol 2012; 14: 819-29.

62. Kim KW, Myers CJ, Jung DK, Lu B. NVP-BEZ-235 enhances radio sensitization via blockade of the PI3K/mTOR pathway in cisplatin-resistant non-small cell lung carcinoma. Genes Cancer 2014; 5: 293-302.

63. Brachmann SM, Hofmann I, Schnell C, et al. Specific apoptosis induction by the dual PI3K/mTor inhibitor NVP-BEZ235 in HER2 amplified and PIK3CA mutant breast cancer cells. Proc Natl Acad Sci U S A 2009; 106: 22299-304.

64. Giampaolo Tortora RB. Overcoming resistance to molecularly targeted anticancer therapies: Rational drug combinations based on EGFR and MAPK inhibition for solid tumours and haemato logic malignancies. Drug Resist Updat Rev Comment Antimicrob Anticancer Chemother 2007; 10: 81-100.

65. Kessler T, Sahm F, Blaes J, Osswald M, Rübmann P, Milford D, Urban S, Jestaedt L. Glioma cell VEGFR-2 confers resistance to chemotherapeutic and antiangiogenic treatments in PTEN-deficient glioblastoma. Oncotarget 2015; 6: 31050-68.

66. Papadopoulos K, Tabernero J, Markman B, et al. Phase I safety, pharmacokinetic and pharmacodynamic study of SAR245409 (XL765), a novel, orally administered PI3K/mTOR inhibitor in patients with advanced solid tumors. Clin Cancer Res 2014; 20 : 2445-56.

67. Bendell JC, Rodon J, Burris HA, et al. Phase I, dose-escalation study of BKM120, an oral pan-Class I PI3K inhibitor, in patients with advanced solid tumors. J Clin Oncol 2012; 30: 282-90.

68. Yu P, Laird AD, Du X, et al. Characterization of the activity of the $\mathrm{PI3K} / \mathrm{mTOR}$ inhibitor XL765 (SAR245409) in tumor models with diverse genetic alterations affecting the PI3K pathway. Mol Cancer Ther 2014; 13: 1078-91.

69. Lau D, Magill ST, Aghi MK. Molecularly targeted therapies for recurrent glioblastoma: current and future targets. Neurosurg Focus 2014; 37: E15.

70. LV S, Teugels E, Sadones J, et al. Correlation of EGFR, IDH1 and PTEN status with the outcome of patients with recurrent glioblastoma treated in a phase II clinical trial with the EGFR-blocking monoclonal antibody cetuximab. Int J Oncol 2012; 41: 1029-35.

71. Qaddoumi I, Kocak M, PaiPanandiker AS, et al. Phase II Trial of Erlotinib during and after Radiotherapy in Children with Newly Diagnosed High-Grade Gliomas. Front Oncol 2014; 4: 67.

72. Wen PY, Chang SM, Lamborn KR, et al. Phase I/II study of erlotinib and temsirolimus for patients with recurrent malignant gliomas: North American Brain Tumor Consortium trial 04-02. Neuro Oncol 2014; 16: 567-78.

73. Westphal M, Heese O, Steinbach JP, et al. A randomised, open label phase III trial with nimotuzumab, an anti-epidermal growth factor receptor monoclonal antibody in the treatment of newly diagnosed adult glioblastoma. Eur J Cancer 2015; 51: 522-32.

74. Schiff D, Kesari S, de Groot J, et al. Phase 2 study of CT-322, a targeted biologic inhibitor of VEGFR-2 based on a domain of human fibronectin, in recurrent glioblastoma. Invest New Drugs 2015; 33: 247-53.

75. Gan HK, Fichtel L, Lassman AB, et al. A phase 1 study evaluating ABT-414 in combination with temozolomide (TMZ) for subjects with recurrent or unresectableglioblastoma (GBM). J Clin Oncol 2014; 32: (suppl; abstr 2021): 5s.

76. Chakravarti A, Wang M, Robins HI, et al. RTOG 0211: a phase $1 / 2$ study of radiation therapy with concurrent gefitinib for newly diagnosed glioblastoma patients. Int J Radiat Oncol Biol Phys 2013; 85: 1206-11.

77. De Groot JF, Lamborn KR, Chang SM, et al. Phase II study of aflibercept in recurrent malignant glioma: a North American Brain Tumor Consortium study. J Clin Oncol 2011; 29: 2689-95.

78. Gerstner ER, Eichler AF, Plotkin SR, et al. Phase I trial with biomarker studies of vatalanib (PTK787) in patients with newly diagnosed glioblastoma treated with enzyme inducing anti-epileptic drugs and standard radiation and temozolomide. J Neurooncol 2011; 103: 325-32.

79. Lassman AB, Pugh SL, Gilbert MR, et al. Phase 2 trial of dasatinib in target-selected patients with recurrent glioblastoma (RTOG 0627). Neuro Oncol 2015; 17: 992-8.

80. Hutterer M, Nowosielski M, Haybaeck J, et al. A single-arm phase Il Austrian/German multicenter trial on continuous daily sunitinib in primary glioblastoma at first recurrence (SURGE 01-07). Neuro Oncol 2014; 16: 92-102.

81. Hottinger AF, Aissa AB, Espeli V, et al. Phase I study of sorafenib combined with radiation therapy and temozolomide as first-line treatment of high-grade glioma. Br J Cancer 2014; 110: 2655-61.

82. Karajannis MA, Legault G, Fisher MJ, et al. Phase II study of sorafenib in children with recurrent or progressive low-grade astrocytomas. Neuro Oncol 2014; 16: 1408-16.

83. Coxon A, Ziegler B, Kaufman S, et al. Antitumor activity of motesanib alone and in combination with cisplatin or docetaxel in multiple human non-small-cell lung cancer xenograft models. Mol Cancer 2012; 11: 70.

84. Kreisl TN, McNeill KA, Sul J, Iwamoto FM, Shih J, Fine HA. A phase I/II trial of vandetanib for patients with recurrent malignant glioma. Neuro Oncol 2012; 14: 1519-26.

85. Lee EO, Kaley TJ, Duda DG, et al. A multicenter, phase II, randomized, non-comparative clinical trial of radiation and temozolomide with or without vandetanib in newly-diagnosed glioblastoma patients. Clin Cancer Res 2015; 21: 3610-8. 
86. Iwamoto FM, Lamborn KR, Robins HI, et al. Phase II trial of pazopanib (GW786034), an oral multi-targeted angiogenesis inhibitor, for adults with recurrent glioblastoma (North American Brain Tumor Consortium Study 06-02). Neuro Oncol 2010; 12: 855-61.

87. Taylor JW, Dietrich J, Gerstner ER, et al. Phase 2 study of bosu tinib, a Src inhibitor, in adults with recurrent glioblastoma. J Neurooncol 2015; 121: 557-63.

88. Blay J-Y, Shen L, Kang Y-K, et al. Nilotinib versus imatinib as firstline therapy for patients with unresectable or metastatic gas trointestinal stromal tumours (ENESTg1): a randomised phase 3 trial. Lancet Oncol 2015; 16: 550-60.

89. Lu L, Saha D, Martuza RL, Rabkin SD, Wakimoto H. Single agent efficacy of the VEGFR kinase inhibitor axitinib in preclinical mod els of glioblastoma. J Neurooncol 2015; 121: 91-100.

90. Gil del Alcazar CR, Hardebeck MC, Mukherjee B, et al. Inhibition of DNA double-strand break repair by the dual PI3K/mTOR inhib itor NVP-BEZ235 as a strategy for radiosensitization of glioblastoma. Clin Cancer Res 2014; 20: 1235-48

91. Chinnaiyan P, Won M, Wen PY, et al. RTOG 0913: a phase 1 study of daily everolimus (RAD001) in combination with radiation therapy and temozolomide in patients with newly diagnosed glioblastoma. Int J Radiat Oncol Biol Phys 2013; 86: 880-4

92. Lassen U, Sorensen M, Gaziel TB, Hasselbalch B, Poulsen HS. Phase II study of bevacizumab and temsirolimus combination therapy for recurrent glioblastomamultiforme. Anticancer Res 2013; 33: 1657-60.

93. Jane EP, Premkumar DR, Morales A, Foster KA, Pollack IF. Inhibition of phosphatidylinositol 3-kinase/AKT signaling by NVPBKM120 promotes ABT-737-induced toxicity in a caspase-dependent manner through mitochondrial dysfunction and DNA damage response in established and primary cultured glioblastoma cells. J Pharmacol Exp Ther 2014; 350: 22-35.

94. Zhang Y, Guessous F, Kofman A, Schiff D, Abounader R. XL-184, a MET, VEGFR-2 and RET kinase inhibitor for the treatment of thyroid cancer, glioblastomamultiforme and NSCLC. I Drugs Investig Drugs J 2010; 13: 112-21.

95. Singh AR, Joshi S, George E, Durden DL. Anti-tumor effect of a novel PI3-kinase inhibitor, SF1126, in 12 V-Ha-Ras transgenic mouse glioma model. Cancer Cell Int 2014; 14: 105.

96. Ekshyyan O, Anandharaj A, Nathan C-AO. Dual PI3K/mTOR Inhibitors: does p53 modulate response? Clin Cancer Res 2013; 19: 3719-21.

97. Brain Tumor News: Early Results of Phase 2 Trial of Perifosine (KRX-0401) for the Treatment of Recurrent Malignant Gliomas Presented at the 12th Annual Scientific Meeting of Society for Neuro-Oncology 2015; poster presentation.

98. Kahn J, Hayman TJ, Jamal M, Rath BH, Kramp T, Camphausen K, Tofilon PJ. The mTORC1/mTORC2 inhibitor AZD2014 enhances the radiosensitivity of glioblastoma stem-like cells. Neuro Oncol 2014; 16: 29-37.

99. Narla RK, Peng S, Gamez J, Katz J, Apuy J, Moghaddam M. Antitumor activity of mTOR kinase inhibitor CC-223 in a mouse mode of glioblastoma 2014; 12 (11 Supplement): A165-A165.

100. Lee E, TORC1/2 Inhibitor INK128 Before and After Surgery in Treating Patients With Recurrent Glioblastoma - ClinicalTrials: NCT02133183.

101. He K, Zheng X, Li M, Zhang L, Yu J. mTOR inhibitors induce apoptosis in colon cancer cells via CHOP-dependent DR5 induction on 4E-BP1 dephosphorylation. Oncogene 2015; doi: 10.1038/ onc.2015.79.

102. Tai S, Sun Y, Liu N, et al. Combination of Rad001 (everolimus) and propachlor synergistically induces apoptosis through enhanced autophagy in prostate cancer cells. Mol Cancer Ther 2012; 11: 1320-31.

103. Lu B, Li J, Pan J, Huang B, Liu J, Zheng D. Everolimus enhances the cytotoxicity of bendamustine in multiple myeloma cells through a network of pro-apoptotic and cell-cycle-progression regulatory proteins. Acta Biochim Biophys Sin 2013; 45: 683-91.

104. Orlowski RZ. Novel Agents for Multiple Myeloma to Overcome Resistance in Phase III Clinical Trials. Semin Oncol 2013; 40: 10.

105. Liu J, Lin A. Role of JNK activation in apoptosis: A double-edged sword. Cell Res 2005; 15: 36-42.
106. Fei H, Chen G, Wang J, Wang F. Perifosine induces cell cycle arrest and apoptosis in human hepatocellular carcinoma cell lines by blockade of Akt phosphorylation. Cytotechnology 2010; 62: 449-60.

107. Broekman F, Giovannetti E, Peters GJ. Tyrosine kinase inhibitors: Multi-targeted or single-targeted? World J Clin Oncol 2011; 2: 80-93.

108. Reardon DA, Turner S, Peters KB, et al. A Review of VEGF/VEG FR-Targeted Therapeutics for Recurrent Glioblastoma. J Natl Compr Canc Netw 2011; 9: 414-27.

109. Liu L, Cao Y, Chen C, et al. Sorafenib blocks the RAF/MEK/ERK pathway, inhibits tumor angiogenesis, and induces tumor cell apoptosis in hepatocellular carcinoma model PLC/PRF/5. Cancer Res 2006; 66: 11851-8

110. Song L, Morris M, Bagui T, Lee FY, Jove R, Haura EB. Dasatinib (BMS-354825) selectively induces apoptosis in lung cancer cells dependent on epidermal growth factor receptor signaling for survival. Cancer Res 2006; 66: 5542-8.

111. Truffaux N, Philippe C, Paulsson J, et al. Preclinical evaluation of dasatinib alone and in combination with cabozantinib for the treatment of diffuse intrinsic pontineglioma. Neuro Oncol 2015; 17: 953-64.

112. Druker BJ. Perspectives on the development of a molecularly targeted agent. Cancer Cell 2002; 1: 31-6.

113. Pennacchietti S, Michieli P, Galluzzo M, Mazzone M, Giordano S, Comoglio PM. Hypoxia promotes invasive growth by transcriptional activation of the met protooncogene. Cancer Cell 2003; 3 : 347-61.

114. Chen Y, Fu L. Mechanisms of acquired resistance to tyrosine kinase inhibitors. Acta Pharm Sin B 2011; 1: 197-207.

115. Fenton TR, Nathanson D, Ponte de Albuquerque C, et al. Resis tance to EGF receptor inhibitors in glioblastoma mediated by phosphorylation of the PTEN tumor suppressor at tyrosine 240. Proc Natl Acad Sci U S A 2012; 109: 14164-9.

\section{Address for correspondence}

\section{Anica Dricu}

University of Medicine and Pharmacy of Craiova

Petru Rareş Street

200349 Craiova, Romania

tel. $+40351-443500$

e-mail: anica.dricu@live.co.uk

Submitted: 26.05 .2015

Accepted: $\quad 15.10 .2015$ 